\title{
High dose versus low dose Aspirin after Percutaneous Coronary Intervention in Coronary Artery Disease
}

\author{
Rajib Rajbhandari', Rikesh Tamrakar', Yuba Raj Limbu', Satish Singh ${ }^{1}$, Sanjay Singh KC ${ }^{1}$ \\ ${ }^{1}$ Department of Cardiology, Shahid Gangalal National Heart Center, Bansbari, Nepal
}

Corresponding Author: Rajib Rajbhandari,

Department of Cardiology, Shahid Gangalal National Heart Center,

Bansbari, Nepal

Email: rajibrbhandari@yahoo.com

ORCID ID NO: 0000-0003-4103-3119

Cite this article as: Rajbhandari R., Tamrakar R., Limbu Y. R., et al. High dose versus low dose Aspirin after Percutaneous Coronary Intervention in Coronary Artery Disease. Nepalese Heart Journal 2019; Vol 16 (2), 59-62

Submission date: $20^{\text {th }}$ September 2019

Accepted date: $5^{\text {th }}$ November 2019

\section{Abstract}

Background and Aims: Patients with Coronary artery disease who undergo percutaneous coronary intervention (PCI) are prescribed with maintenance aspirin dose that vary between $75 \mathrm{mg}$ to $300 \mathrm{mg}$ daily. The objective of this study is to evaluate the effects of high dose versus low dose aspirin doses prescribed on hospital discharge in PCI.

Methods: : All the patients who had undergone PCI at our hospital from 2017 February to October 2017 were enrolled in the study. They were divided into two groups receiving low dose $(<200 \mathrm{mg})$ aspirin and high dose $(>200 \mathrm{mg})$ aspirin. Patients were interviewed on phone after completion of one year for the possible complications and new ischemic events during the follow up period.

Results: Among 150 patients selected 101 fulfilled the criteria and sixty patients (59.4\%) were discharged on low-dose aspirin $75-150 \mathrm{mg}$ and 41 patients $(40.6 \%)$ were discharged on high-dose aspirin of $300 \mathrm{mg}$. The mean age in low aspirin group was $59.8 \pm 13.19$ years and $49.4 \pm 10.7$ years in high aspirin group. Although high aspirin dose patients did not complain of epigastric pain more often, upper GI bleeding was significantly higher in high aspirin group $7.5 \%$ vs $11.1 \%(\mathrm{p}<0.05)$. One patient in high aspirin group had hemorrhagic stroke while low aspirin group had none. One patient in high aspirin had sudden cardiac death at home. Clinically, there was no significant difference in new ischemic events during follow up period. Conclusion: In patients with coronary artery disease undergoing PCI, discharge on high-dose rather than low-dose aspirin may increase the rate of bleeding without providing additional ischemic benefit.

Keywords: APD acid peptic disease, CAD coronary artery disease, CV cardiovascular, GI gastrointestinal, PCI percutaneous coronary intervention.

DOI: https://doi.org/10.3126/njh.v16i2.26319

\section{Introduction}

Patients with coronary artery disease who undergo percutaneous coronary intervention (PCI) are prescribed with maintenance aspirin dose that vary between $75 \mathrm{mg}$ to $325 \mathrm{mg}$ daily ${ }^{1-3}$. How the aspirin dose affects long term outcome is not clear although few studies have demonstrated low dose to be safer in comparison to high dose ${ }^{4-}$ ${ }^{6}$. And the optimal long term maintenance dose of aspirin in patients undergoing primary PCI for ST-segment elevation myocardial infarction (STEMI) and elective PCI had not been studied till recently.
Pharmacologically maximal inhibition of thromboxane-mediated platelet activation is achieved with aspirin doses as low as $30 \mathrm{mg}^{7}$, It is often felt that the high dose of aspirin administered to these patients do not provide further protection in ischemic events but rather may affect the patients during procedures like dental extraction, prostate surgery, cholecystectomy etc. So, it is sometimes quite essential that the dose of aspirin is reduced to as low as possible so that the bleeding complication is low. Similarly, many people in our region has acid peptic disease in which people would not tolerate high dose of aspirin. The objective of this study is to evaluate the effects of

(a) Nepalese Heart Journal. Nepalese Heart Journal retain copyright and works is simultaneously licensed under Creative Commons Attribution License CC - By 4.0 that allows others to share the work with an acknowledge of the work's authorship and initial publication in this journal

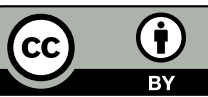


low dose versus high aspirin prescribed at hospital discharge in the patients undergoing PCI.

\section{Methods}

The present study is a retrospective $2 \times 2$ factorial single centre trial to evaluate the low dose of aspirin $(75-150 \mathrm{mg})$ in comparison to high dose $(300 \mathrm{mg})$ after PCI. For current analysis, aspirin dose less than $200 \mathrm{mg}$ was defined as low dose and more than 200 was defined as high dose. This cutoff point was based on similar previous landmark studies $^{8-10}$. All the patients who had undergone PCI at our hospital from 2017 February to October 2017 were enrolled in the study. Patients either received $75-150 \mathrm{mg}$ of aspirin (low dose) or $300 \mathrm{mg}$ of aspirin (high dose). All of the patients received $75 \mathrm{mg}$ clopidogrel, 10-40 $\mathrm{mg}$ statins (atorvastatin or rosuvastatin) and betablocker and angiotensin converting enzymes inhibitors/Angiotensin receptor blockers as per indication. Patients who had undergone primary PCI received $600 \mathrm{~g}$ of clopidogrel and $300 \mathrm{mg}$ of aspirin prior to the procedure. Those undergoing elective PCI were taking regular clopidogrel of $75 \mathrm{mg}$ and aspirin $75 \mathrm{mg}$ before the procedure. Patients in high dose aspirin group took $300 \mathrm{mg}$ for 6 months then the dose was reduced to $150 \mathrm{mg}$ after 6 months. Patients in low aspirin group took $75-150 \mathrm{mg}$ for at least one year. All the patient had used minimum of $100 \mathrm{U}$ heparin / $\mathrm{kg}$ and few patients received few more thousand units added if the activated clotting time (ACT) was less than 360 seconds. None of the patients used ticagrelor or prasugrel or GpIIbIIIa inhibitors. All patients were using either evorilimus or zotarilimus drug eluting stents (DES). Those patients having renal dysfunction, history of cerebral vascular accidents, who were on oral anticoagulants who were noncompliant to medications, those having a history of peptic ulcer were excluded from the study.

All these patients were interviewed on phone after completion of one year of their procedure. They were inquired for the possible complications. The questionnaire is discussed with the patient to assess whether patient had any angina on exertion, gastrointestinal symptoms or GI bleeding. They were inquired whether they passed black tarry stool in the last one year. They were asked whether they were admitted in the hospital for gastrointestinal bleed and what investigation they underwent.

Major bleeding was considered as those who needed blood transfusion. Symptoms of acid peptic didease APD was subjectively assessed through questionnaire. The signs and symptoms of cerebral stroke admission to other hospital were also enquired. And symptoms of severe chest pain suggestive of coronary ischemia was particularly asked to the patient and possibility of stent thrombosis was judged.

Institutional review board approved the trial protocol and patients provided verbal consent for the study.

All statistical analysis was done as retrospective posthoc analysis. All analyses were by intention to treat. Categorical variables were compared using pearson's chi-square wherever feasible. Baseline characteristics were also compared between 2 groups by Pearsons $2 \times 2$ test (SAS version 9.2)

\section{Results}

Among 150 patients screened, 101 patients were included as they fit in the criteria. Sixty patients (59.4\%) of the patients were discharged on low-dose aspirin and forty-one patients $(40.6 \%)$ patients were discharged on high-dose aspirin group. All the patient in high dose group received $300 \mathrm{mg}$ for 6 months and $150 \mathrm{mg}$ for another 6 months. Among patients in low dose group, $85 \%$ of patients received $150 \mathrm{mg}$ and $15 \%$ of the patient received $75 \mathrm{mg}$. Aspirin doses in low dose group were guided by the routine clinical practice. Mean age in low dose aspirin group was $59.8 \pm 13.19$ years and mean age in high dose aspirin group $49.4 \pm 10.7$ years.

The prevalence of smoking was more in low dose group in comparison to high dose aspirin group ( $41.4 \%$ vs $25.0 \%)$; though this could just be a incidental finding. Upper GI bleeding was significantly higher in high dose aspirin group $7.5 \%$ vs $11.1 \%(\mathrm{p}<0.05)$ although high dose aspirin patients did not complain of epigastric pain more often.

Patients complaining of chest pain (angina on exertion or chest pain with sweating) was present in similar number in both the groups high and low dose. Patients attending hospital for chest pain was slightly high in low dose aspirin group however this was not statistically significant ( $\mathrm{p}$ value was 0.3 by Fischer Exact test). One had reocclusion of stent with thrombosis. One patient on high dose aspirin group had hemorrhagic stroke while low dose aspirin group had none and one patient in high dose aspirin had sudden cardiac death at home

Table 1: Aspirin doses and different risk factors:

\begin{tabular}{llll|}
\hline Risk factors & $\begin{array}{l}\text { High dose } \\
\text { group }\end{array}$ & $\begin{array}{l}\text { Low dose } \\
\text { group }\end{array}$ & \\
\hline $\begin{array}{l}\text { Mean age in years } \\
\text { (SD) }\end{array}$ & $49.4( \pm 10.7)$ & $59.8( \pm 13.19)$ & \\
\hline Male sex & 57.1 & 68 & \\
\hline Diabetes & 14 & 26 & \\
\hline $\begin{array}{l}\text { Hypertension } \\
\text { Dyslipidemia }\end{array}$ & 2 & 50 & $\mathrm{p} 0.01$ \\
\hline Smoking & 25 & 0 & $\mathrm{p}<0.05$ \\
\hline $\begin{array}{l}\text { Family history of } \\
\text { CAD }\end{array}$ & 32 & 71 & $\mathrm{P}<0.05$ \\
$\begin{array}{l}\text { Multiple stents } \\
\text { used }\end{array}$ & 35 & 19 & \\
\hline
\end{tabular}

Table 2: Complications and efficacy

\begin{tabular}{|c|c|c|c|}
\hline Complications and efficacy & $\begin{array}{l}\text { High } \\
\text { dose }\end{array}$ & $\begin{array}{l}\text { Low } \\
\text { dose }\end{array}$ & \\
\hline $\begin{array}{l}\text { GI bleeding not requiring transfu- } \\
\text { sion but attended medical service }\end{array}$ & $11.1 \%$ & $7.5 \%$ & $\mathrm{p}<0.05$ \\
\hline GI bleeding requiring transfusion & 0 & 0 & \\
\hline $\begin{array}{l}\text { Access site hematoma causing } \\
\text { pain requiring medical attention }\end{array}$ & $1.6 \%$ & 0 & $\mathrm{p}<0.2$ \\
\hline $\begin{array}{l}\text { Access site hematoma requiring } \\
\text { hospital admission }\end{array}$ & $15 \%$ & $17 \%$ & $\mathrm{p}=\mathrm{NS}$ \\
\hline Hemorrhagic stroke & $1.6 \%$ & 0 & $\mathrm{p}=\mathrm{NS}$ \\
\hline $\begin{array}{l}\text { Chest pain while at home (not } \\
\text { attending hospital ER) }\end{array}$ & $15 \%$ & $16 \%$ & $\mathrm{p}=\mathrm{NS}$ \\
\hline Chest pain attending hospital & $5 \%$ & $6.5 \%$ & $\mathrm{p}=0.3$ \\
\hline $\begin{array}{l}\text { Probable stent thrombosis (Sud- } \\
\text { den cardiac death) }\end{array}$ & 0 & 1 & $\mathrm{p}=\mathrm{NS}$ \\
\hline Radial approach used & $60 \%$ & $56 \%$ & $\mathrm{p}=\mathrm{NS}$ \\
\hline
\end{tabular}




\section{Discussions}

The study has highlighted the current practice of aspirin dosing among the cardiologists. In our study, selection of high vs low aspirin was not according to presence of risk factors like diabetes, hypertension or smoking. The low dose aspirin group had more conventional risk factors. We also found the trend that dose correlated positively with complexity of the procedure. High dose aspirin was used more often in multiple stent PCI rather than single stent PCI. All these observations point that dose of aspirin after procedure was likely the individual choice of operator rather than based from present guidelines.

We consider passing of black stool is considered as upper gastrointestinal (UGI) bleeding due to aspirin because this is the most common of UGI bleeding in patient taking aspirin. They are classified as those requiring or not requiring blood transfusion. Similar tool for analysis of UGI bleeding has been done in other studies we believe that it will reflect overall true picture.

The history of typical chest pain was taken in detail and considered to be probably from coronary events because of their vulnerable post PCI status. The sudden unexplained death is considered to be due to cardiovascular event. These indirect inferences may carry confounding bias. Only large scale randomized prospective trial in our region addressing with a better accessibility to the patient can address this issue.

In our study, the patients undergoing PCI for coronary artery disease (CAD) discharged on and maintained chronically high-dose aspirin had similar rates of adverse ischemic symptoms but significantly more major bleeding than did patients on low-dose aspirin. Therefore, this analysis supports the practice and the notion that patients with CAD undergoing PCI should be maintained on low-dose rather than highdose aspirin.

Observational analyses performed using data from the Clopidogrel in Unstable Angina to Prevent recurrent Events (CURE) trial demonstrated no significant difference in efficacy for low-dose aspirin ( $\leq 100 \mathrm{mg}$ ) versus high-dose aspirin $(\geq 200 \mathrm{mg}$ ), but an increase in bleeding complications with high-dose aspirin. Findings were similar among patients prescribed aspirin monotherapy versus dual antiplatelet treatment with aspirin and clopidogrel ${ }^{11}$.

The results of the Double-dose versus Standard-dose Clopidogrel and High-dose versus Low-dose Aspirin in Individuals undergoing Percutaneous Coronary Intervention for Acute Coronary Syndromes (CURRENT- OASIS 7) trial revealed no significant differences in major adverse cardiac events between patients with acute coronary syndrome randomized to high $(300-325 \mathrm{mg})$ versus low-dose (75$100 \mathrm{mg}$ ) aspirin. Although overall bleeding complications were not significantly different between the two aspirin groups, there was a higher incidence of gastrointestinal bleeding with high-dose aspirin compared with low-dose aspirin ${ }^{12}$.

Similarly, in the older Antithrombotic Trialists' meta-analysis, high-dose aspirin was associated with increased gastrointestinal and extracranial bleeding but no improvement in efficacy. Together, these data suggest that low-dose aspirin is safer and provides similar efficacy versus high-dose aspirin ${ }^{13}$.

\section{Limitations of the study}

This is small sample size study and had limited duration of follow up. As a post hoc analysis, the findings from the current study is exploratory. Multivariate analysis could not be done. Unmeasured confounding variables may have biased the comparison. Logistic regression analysis which was used in few similar trials could not be used because of small size of the patient population. The way patient described about UGI bleeding is subjective. Primary and elective
PCI was not separately analyzed in the study. The possibility of stent thrombosis was not confirmed with angiography in all cases.

\section{Conclusion}

In patients with coronary artery disease undergoing PCI, discharged on high-dose aspirin, in comparison to low-dose aspirin, increases the rate of bleeding without providing additional ischemic benefit. Large scale prospective trial is needed to support these facts.

\section{Sources of funding: None}

\section{Conflict of Interest: None}

\section{References}

1. Faroukn ME. Relationship between ST-segment recovery and clinical outcomes after primary PCI; The HORIZONS -AMI ECG sub study report. Circ Cardiovasc Interv 2013 https://doi.org/10.1161/CIRCINTERVENTIONS.112.000142

2. Rene AG. Impact of aspirin in patients with ST-elevation MI treated with PCI. Am J cardiol. 2014

3. Genereux P. Ischemic outcome after coronary Intervention of calcified vessels in acute coronary syndrome. Pooled analysis from HORIZONS AMI and ACUIT J Am coll cardial.2014.

4. Xi W.Radial vs. femoral access for primary PCI in ST - segmental elevation MI:meta anatysis of randomized controlled trial.JACC cardiovasc Interv.2013.

5. Mahaffey KW, Wojdyla DM, Carroll K, et al. Ticagrelor compared with clopidogrel by geographic region in the Platelet Inhibition and Patient Outcomes (PLATO) trial. Circulation 2011;124:544 -54. https://doi.org/10.1161/CIRCULATIONAHA.111.047498

6. Investigators. Dose comparisons of clopidogrel and aspirin in acute coronary syndromes. N Engl J Med 2010; 363: 930-42. https://doi.org/10.1056/NEJMoa0909475

7. Derry S, Loke YK. Risk of gastrointestinal haemorrhage with longterm use of aspirin: meta-analysis.BMJ 2000;321:1183-7 https://doi.org/10.1136/bmj.321.7270.1183

8. CURRENT-OASIS 7 Investigators, Mehta SR, Bassand JP, et al. Dose comparisons of clopidogrel and aspirin in acute coronary syndromes. N Engl J Med. 2010; 363 (10):930-42. https://doi.org/10.1056/NEJMoa0909475

9. Jolly SS, Pogue J, Haladyn K, et al. Effects of aspirin dose on ischaemic events and bleeding after percutaneous coronary intervention: insights from the PCI-CURE study. Eur Heart J. 2009; 30(8):900-7. doi:10.1093/eurheartj/ehn417. https://doi.org/10.1093/eurheartj/ehn417

10. Yu J, Mehran R, Dangas GD, et al. Safety and efficacy of high- versus low-dose aspirin after primary percutaneous coronary intervention in ST-segment elevation myocardial infarction: the HORIZONS-AMI (Harmonizing Outcomes With Revascularization and Stents in Acute Myocardial Infarction) trial. JACC Cardiovasc Interv. 
2012; 5(12):1231-8.

https://doi.org/10.1016/j.jcin.2012.07.016

11. Peters RJ, Mehta SR, Fox KA, et al. Clopidogrel in Unstable angina to prevent Recurrent Events (CURE) Trial Investigators. Effects of aspirin dosewhen used alone or in combination with clopidogrel in patients with acute coronary syndromes: observations from the Clopidogrel in Unstable angina to prevent Recurrent Events (CURE) study. Circulation. 2003; 108: 1682-1687.

https://doi.org/10.1161/01.CIR.0000091201.39590.CB
12. Mehta SR, Tanguay JF, Eikelboom JW, et al. CURRENT OASIS 7 trial investigators. Double-dose versus standarddose clopidogrel and high-dose versus low-dose aspirin in individuals undergoing percutaneous coronary intervention for acute coronary syndromes (CURRENTOASIS 7): a randomised factorial trial. Lancet. 2010; 376:1233-1243. https://doi.org/10.1016/S0140-6736(10)61088-4

13. Baigent C, Blackwell L, Collins R, et al Antithrombotic Trialists' (ATT) Collaboration. Aspirin in the primary and secondary prevention of vascular disease: collaborative metaanalysis of individual participant data from randomised trials. Lancet. 2009; 373:1849-1860.

https://doi.org/10.1016/S0140-6736(09)60503-1 


\title{
Profile of Non-Diabetic patients with Microalbuminuria in Acute Coronary Syndrome: A hospital based study
}

\author{
Navaraj Paudel ${ }^{1}$, Abhishek Maskey ${ }^{1}$, Dipesh Karki ${ }^{1}$, Sushant Katwal ${ }^{1}$, Namrata Thapa ${ }^{2}$,
}

${ }^{1}$ Department of Internal Medicine, Manipal Teaching Hospital, Pokhara

${ }^{2}$ Manipal School of Nursing, Manipal Teaching Hospital, Pokhara

Corresponding Author: Navaraj Paudel,

Department of Internal Medicine (Cardiology Unit), Manipal Teaching Hospital, Pokhara, Nepal.

Email: drnavarajdm@gmail.com

ORCID ID NO: 0000-0003-4551-0808

Cite this article as: Paudel N., Maskey A., Karki D., et al. Profile of Non-Diabetic patients with Microalbuminuria in Acute Coronary Syndrome: A hospital based study. Nepalese Heart Journal 2019; Vol 16 (2), 63-67

Submission date: $17^{\text {th }}$ July 2019

Accepted date: $7^{\text {th }}$ November 2019

\section{Abstract}

Background and Aims: Microalbuminuria (MA) (urinary albumin excretion of 30-299 mg/d in a 24 hours collection or $30-299 \mu \mathrm{g} / \mathrm{mg}$ creatinine in a spot collection) is well accepted marker of micro and macrovascular damage in patients with diabetes mellitus and is considered as a surrogate marker for endothelial dysfunction in diabetic and non-diabetic patients. This study has been undertaken to investigate the prevalence of microalbuminuria among non-diabetic Acute Coronary Syndrome (ACS) patients.

Methods: : A hospital based cross-sectional study of 100 consecutive non-diabetic ACS patients was done. Traditional risk factors (like smoking, hypertension, dyslipidemia, obesity) of coronary artery disease were studied for the association with microalbuminuria in study subjects. Investigations were carried out in all the cases as per proforma and entered in the SPSS software for analysis.

Results: The prevalence of microalbuminuria in non-diabetic ACS patients in the study was $73 \%$ which was statistically significant $(\mathrm{p}=0.04)$. A statistically significant higher prevalence of microalbuminuria was seen with different presentations of ACS; being highest (81.96\%) in NSTEMI followed by STEMI (63.15\%) and Unstable Angina (55\%). It was found to be significant with the history of smoking $(81.25 \%, \mathrm{p}=0.013)$ and hypertension $(82.25 \%, \mathrm{p}=0.013)$. No significant association was found with age, body mass index (BMI) and dyslipidemia. A statistically significant higher prevalence of microalbuminuria was seen with increasing number of risk factors.

Conclusion: There is increased prevalence of microalbuminuria in ACS patents. MA was associated with statistically higher number of cases with history of smoking and hypertension and presence of increasing number of risk factors.

Keywords: Acute Coronary Syndrome, Microalbuminuria, Traditional risk factors.

DOI: https://doi.org/10.3126/njh.v16i2.26320

\section{Introduction}

Microalbuminuria (MA) is defined as increased urinary albumin excretion of 30-299 mg/d in a 24 hours collection or 30-299 $\mu \mathrm{g} / \mathrm{mg}$ creatinine in a spot collection ${ }^{1}$.

Evidence has shown an early increase of urinary albumin in acute myocardial infarction is a strong independent predictor of long-term adverse clinical outcome and Albumin Creatinine Ratio (ACR) improved clinical prediction over and above baseline traditional multivariable risk models" . The study on "Relationship between MA and the Presence and Extent of Coronary Atherosclerosis" found MA to be an independent predictor for the presence and severity of CAD. They concluded a strong relationship between MA and the severity of $\mathrm{CAD}^{3}$. Some studies show patients with higher proteinuria are at risk of developing higher degrees of ACS with adverse outcomes ${ }^{3,4}$.

There is a study regarding outcomes in ACS patients in Nepal taking in consideration of ACS patients only (including all the risk factors) $)^{5}$. We know that diabetes is an established cause of

(a) Nepalese Heart Journal. Nepalese Heart Journal retain copyright and works is simultaneously licensed under Creative Commons Attribution License CC - By 4.0 that allows others to share the work with an acknowledge of the work's authorship and initial publication in this journal

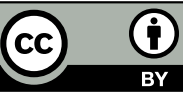


endothelial dysfunction (ED) and its presence is considered as coronary artery disease equivalent. Hence to minimize confounding bias, we wanted to exclude diabetes (however other risk factors like hypertension and dyslipidemia are included). So, this study aims to find an association of MA in non-diabetic ACS patients admitted in Manipal Teaching Hospital which may represent patients of western region of Nepal being a referral center for ACS.

\section{Methods}

It was a cross-sectional observational study. One hundred (100) consecutive patients of Acute Coronary Syndrome admitted in Manipal Teaching Hospital were included in this study. Patient included in this study were: Acute Coronary Syndrome included patients with 1. ST Elevation Myocardial Infarction (STEMI) 2. Non ST Elevation Myocardial Infarction (NSTEMI). 3. Unstable Angina (UA).

The diagnostic criteria used for each were as under: 1) ST Elevation Myocardial Infarction (STEMI): Cases fulfilling two of the following three criteria- a) History of prolonged chest discomfort or angina equivalent (30 minutes). b) ST-elevation $1 \mathrm{~mm}$ or more in two consecutive leads or new onset Left Bundle Branch Block (LBBB). c) Presence of elevated cardiac biomarkers. 2) Non ST Elevation Myocardial Infarction (NSTEMI): Severe chest discomfort having at least one of three features along with evidence of myocardial necrosis as reflected by abnormally elevated levels of biomarkers of cardiac necrosis. i) Occurring at rest (or with minimal exertion), lasting for $>10$ minutes ii) Recent onset (i.e. within the prior 2 weeks) iii) Occurring with crescendo pattern (i.e. distinctly more severe, prolonged, or frequent than previous episodes. 3) Unstable Angina (UA): Angina pectoris or equivalent ischemic discomfort with at least one of three features: i) Occurring at rest (or with minimal exertion), lasting for $>10$ minutes ii) Recent onset (i.e. within the prior 2 weeks) iii) Occurring with crescendo pattern (i.e. distinctly more severe, prolonged, or frequent than previous episodes. The following cases were excluded: 1 . Known cases of diabetes mellitus. Cases showing random blood sugar $\geq 200 \mathrm{mg} / \mathrm{dl}$. 3 . MA $>300 \mathrm{mg} \mu \mathrm{g} / \mathrm{mg}$ creatinine. 4 . Serum Creatinine $>1.5 \mathrm{mg} / \mathrm{dl}$. 5 . Patients showing pyuria with urine microscopy showing $\geq 8 \mathrm{WBC} / \mathrm{hpf}$. Patients with history of preexisting congestive cardiac failure.

Urine examination was carried out for all patients. a) Routine and microscopy b) MA by Nyocard kit test. The patients were explained about the procedure of urine specimen collection. Urine spot test was opted for assessment of MA for feasibility. Early morning midstream specimen was collected after washing the penile area in males, and perineal area in females. All urine specimens were obtained aseptically in well labeled screw capped universal containers and were promptly transported to laboratory for routine and microscopy examination and MA estimation.

The data was entered in excel sheet and analyzed using SPSS software version 16. Percentage, mean value were calculated and Pearson's correlation coefficient, chi square test, t-tests, odds ratio etc were calculated wherever required and $\mathrm{p}$ values were considered significant at a predetermined alpha level of $5 \%$.

\section{Results}

Total 100 patients were studied in this study. Out of them 68 were males while 32 were females with male: female $=2.12$. Majority of patients had NSTEMI: $61 \%(\mathrm{n}=61), 20 \%(\mathrm{n}=20)$ had UA and $19 \%$ $(\mathrm{n}=19)$ had STEMI. Overall prevalence of MA in our study was $73 \%$ $(\mathrm{p}=0.04)$; (Table 1).
Table 1: Overall prevalence of MA in ACS.

\begin{tabular}{|lll|}
\hline Urine & $\begin{array}{l}\text { No of } \\
\text { patients }\end{array}$ & p- value \\
\hline Microalbuminuria & 73 & \\
No microalbuminuria & 27 & 0.04
\end{tabular}

Out of 68 males and 32 females, MA was found positive in 47 $(69.11 \%)$ males and $2(81.25 \%)$ females respectively $(\mathrm{p}=0.202)$; (Table 2).

Table 2: Prevalence of MA among male and female patients.

\begin{tabular}{lllll} 
Urine & $\begin{array}{l}\text { Male } \\
(\mathbf{n = 6 8})\end{array}$ & $\begin{array}{l}\text { Female } \\
(\mathbf{n = 3 2})\end{array}$ & $\begin{array}{l}\text { Odds } \\
\text { ratio }\end{array}$ & $\begin{array}{l}\mathbf{p} \text { - } \\
\text { value }\end{array}$ \\
\hline Microalbuminuria & 47 & 26 & & \\
No microalbuminuria & 21 & 6 & 1.97 & 0.202 \\
\hline
\end{tabular}

The prevalence of MA was highest in NSTEMI group being $81.96 \%$. The corresponding figures in STEMI and Unstable Angina were $63.15 \%$ and $55 \%$ respectively. The difference was statistically significant $(\mathrm{p}=0.035)$.

Table 3: Prevalence of MA in different presentation of ACS

\begin{tabular}{lllll}
$\begin{array}{l}\text { Presenta- } \\
\text { tion } \\
\text { of ACS }\end{array}$ & $\begin{array}{l}\text { Total } \\
(\mathbf{n}=\mathbf{1 0 0})\end{array}$ & $\begin{array}{l}\text { Microal- } \\
\text { buminu- } \\
\text { ria }(\mathbf{n}=\mathbf{7 3})\end{array}$ & $\begin{array}{l}\text { No Microal- } \\
\text { buminuria } \\
(\mathbf{n}=\mathbf{2 7})\end{array}$ & $\begin{array}{l}\mathbf{p}- \\
\text { value }\end{array}$ \\
\hline STEMI & 19 & 12 & 7 & \\
NSTEMI & 61 & 50 & 11 & 0.035 \\
Unstable & 20 & 11 & 9 & \\
Angina & & & &
\end{tabular}

Figure 4: Prevalence of microalbuminuria in different pressentation of ACS

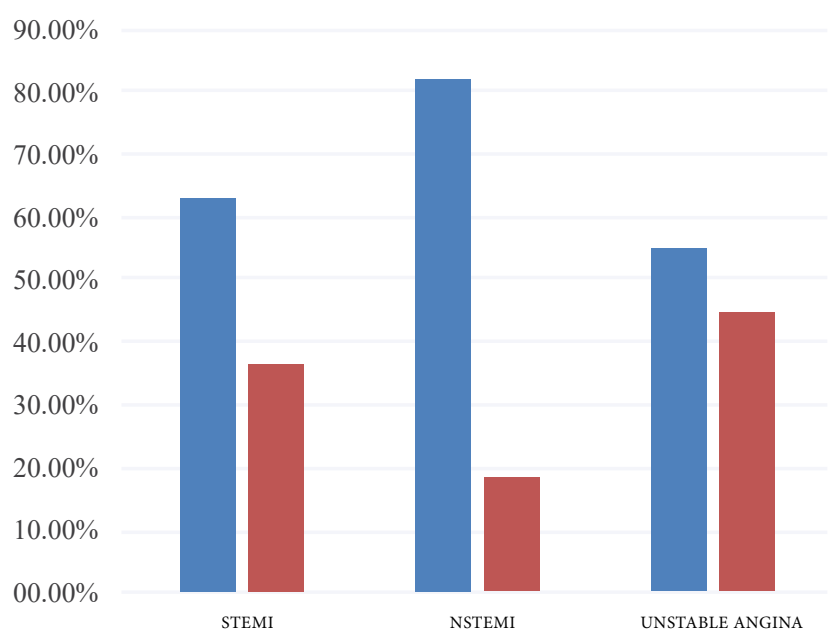


Table 4: Prevalence of MA with risk factors

\begin{tabular}{|c|c|c|c|c|c|}
\hline \multicolumn{3}{|c|}{ Risk factorspatients (n) } & \multirow{2}{*}{$\begin{array}{l}\text { Microalbuminuria } \\
52\end{array}$} & \multirow{2}{*}{$\begin{array}{l}\text { No microalbuminuria } \\
12\end{array}$} & \multirow{3}{*}{$\begin{array}{l}\text { p-value } \\
0.013\end{array}$} \\
\hline Smoking & Yes & 64 & & & \\
\hline & No & 32 & 21 & 11 & \\
\hline \multirow[t]{2}{*}{ Hypertension } & Yes & 62 & 51 & 11 & \multirow[b]{2}{*}{0.013} \\
\hline & No & 38 & 22 & 16 & \\
\hline \multirow[t]{2}{*}{ Obesity (BMI>25Kg/m2) } & Yes & 59 & 45 & 14 & \multirow[t]{2}{*}{0.221} \\
\hline & No & 41 & 28 & 13 & \\
\hline \multirow[t]{2}{*}{ Dyslipidemia } & Yes & 61 & 47 & 14 & \multirow[t]{2}{*}{0.254} \\
\hline & No & 39 & 26 & 13 & \\
\hline
\end{tabular}

98 out of 100 ACS patients were having one or more risk factors under studied. Prevalence of MA was in $50 \%$ of patients with no risk factor, $40 \%$ with one risk factor, $75 \%$ with two risk factors and $86 \%$ with three or more risk factors. The difference was statistically significant $(\mathrm{p}=0.001)$.

Table 5: Relative prevalence of MA in ACS according to number of risk factors.

\begin{tabular}{llll} 
Risk factors & $\begin{array}{l}\text { Total } \\
(\mathbf{n = 1 0 0})\end{array}$ & $\begin{array}{l}\text { Microalbuminuria } \\
(\mathbf{n = 7 3 )}\end{array}$ & $\begin{array}{l}\text { No microalbuminuria } \\
(\mathbf{n = 2 7})\end{array}$ \\
\hline None & $2(2 \%)$ & $1(50 \%)$ & $1(50 \%)$ \\
One & $20(20 \%)$ & $8(40 \%)$ & $12(60 \%)$ \\
Two & $28(28 \%)$ & $21(75 \%)$ & $7(25 \%)$ \\
Three or more & $50(50 \%)$ & $43(86 \%)$ & $7(14 \%)$
\end{tabular}

\section{Discussion}

The overall prevalence of micro-albuminuria in non-diabetic ACS in this study was $73 \%$ which was statistically significant $(\mathrm{p}=0.04)$. The studies done outside also show similar findings ranging from $58-92 \%{ }^{6-10}$. In the study done by $\mathrm{F}$ Aziz et al found prevalence of MA to be $56.5 \%$ in angiographically proved severe CAD (luminal narrowing $>70 \%)^{11}$, Similarly, in the study done by Silva et al on prevalence of MA in 39 patients with angiographically confirmed severe lesion (stenosis $>70 \%$ ) in at least one coronary artery found to be $33 \%$ which was statistically significant ${ }^{12}$. The results of above studies cannot be matched with our study due to different inclusion criteria but nevertheless they confirm the fact that MA is present in statistically significant number of cases in coronary artery disease.

This study showed no difference in MA between different sexes ( $\mathrm{p}$ $=0.202$ ). Few studies ${ }^{13,14}$ also show similar results but a case control study done by Basu et al found a statistically significant higher numbers of males $(83.33 \%)$ as compared to females $(40 \%)^{6}$. In the study done by Silva et al on determination of MA in hypertensive patients and in patients with coronary artery disease found prevalence of MA was $23 \%$ in the age group 56 years and above and $5 \%$ in age group 55 years and below which was statistically significant ${ }^{12}$.

The prevalence of MA was highest in NSTEMI group being $81.96 \%$. The corresponding figures in STEMI and Unstable Angina were $63.15 \%$ and $55 \%$ respectively. The difference was statistically significant ( $\mathrm{p}=0.035)$. Zeeshan A, Ahmad Z, Tahir GA, Yaqoob Y in their study on acute coronary syndrome titled MA as atherosclerotic risk factors and its association found MA in 20.4\% cases of STEMI. The corresponding figures in NSTEMI and Unstable angina were $21.3 \%$ and $25.3 \%$ respectively ${ }^{15}$. In contrast, Abdul Ghaffar Memon and Mubashir Kolachi in their study on relationship of MA in non-diabetic and non-hypertensive patients with acute myocardial infarction done in Hyderabad, Pakistan found MA in 53.17\% STEMI and $15.8 \%$ NSTEMI $^{8}$.

Out of 64 patients with the history smoking in our series, MA was present in $52(81.25 \%)$ while out of 36 nonsmokers, MA was found in $21(58.33 \%)$ patients. The difference was statistically significant $(\mathrm{p}=0.013)$. Basu A et al in their study of 50 non diabetic and non-hypertensive patients of ACS with similar inclusion criteria as our study found MA was present in 92\% (23 out of 25) of patients with smoking while out of 25 nonsmokers, MA was found in $10(40 \%)$ of patients. The difference was statistically significant $(\mathrm{p}<0.001)^{6}$. However Bhalabhi Vaishali and Ghanekar Gayatri in their study of correlation of MA and multiple risk factors in acute coronary syndrome found MA in 50\% (6 out of 12) of patients with smoking which was not statistically significant ( $p$ $>0.05$ ). However cases of diabetes mellitus were also included in their study ${ }^{7}$. Since association of smoking and MA has long been known, further large scale studies are required to determine its association in patients with acute coronary syndrome.

In our study, out of 62 hypertensive patients in our series, MA was present in $51(82.25 \%)$ of the cases while corresponding figures in 38 normotensive patients was $22(57.89 \%)$. The difference was statistically significant $(\mathrm{p}=0.013)$. Bhalabhi Vaishali and Ghanekar Gayatri in their study of correlation of microalbuminuria and multiple risk factors in acute coronary syndrome found microalbuminuria to be present in $8.82 \%$ among hypertensive cases which was not statistically significant $(p>0.05)$. Cases of diabetes mellitus were also included in their study ${ }^{7}$. However, 
Al-Saffar et al in their study of microalbuminuria in non-diabetic patients with Unstable angina/non ST elevation myocardial infarction found microalbuminuria to be present in $8(22 \%)$ of the 37 cases with hypertension while corresponding figures in 33 normotensive patients was $13(39 \%)$. The results were not statistically significant $(\mathrm{p}=0.1)$. ST segment elevation MI cases were not included in their study ${ }^{14}$. Association of microalbuminuria with dyslipidemia and obesity was not significant in our study; however few studies have shown significant association ${ }^{6,15-18} .98$ out of 100 ACS patients in our study were having one or more risk factors. Prevalence of microalbuminuria was in $50 \%$ of patients with no risk factor, $40 \%$ with one risk factor, $75 \%$ with two risk factors and $86 \%$ with three or more risk factors. The difference was statistically significant $(p=0.001)$. In the study done by Bhalavi Vaishali and Ghanekar Gayatri on correlation of microalbuminuria and multiple risk factors in ACS found microalbuminuria in $86.66 \%$ with multiple risk factors compared to $44.44 \%$ with no risk factors and the difference was statistically significant ${ }^{7}$. Massimo Cirillo et al in their of Microalbuminuria in non-diabetic adults showing relation of blood pressure, BMI, plasma cholesterol levels and smoking showed that blood pressure, BMI and smoking relate positively to rate of urinary albumin excretion and prevalence of microalbuminuria independently of each other in nondiabetic middle aged patients ${ }^{19}$. The results of these studies are in agreement with our study.

\section{Conclusion}

Overall prevalence of microalbuminuria in non-diabetic ACS patients in our study was $73 \%$. There is no difference in prevalence of microalbuminuria between males and females. Highest prevalence of microalbuminuria was seen in NSTEMI patients. Microalbuminuria was associated with statistically higher number of cases with history of smoking and hypertension and with increasing number of risk factors present.

\section{Limitations and recommendations}

Our study consisted of 100 patients only and the results of our study need to be substantiated with the results of prospective larger clinical studies with matching clinical criteria.

\section{Sources of funding: None}

\section{Conflict of Interest: None}

\section{References}

1. Powers AC. Diabetes Mellitus Complication. In: Dennis LK, Anthony SF, Longo DL, Loscalzo J, Stephen LH, Jamenson JL, editors. Harrison's Principles of Internal Medicine.19th edn: New York: McGraw-Hill; 2015. p. 2422- 35. doi:10.1001/jama.308.17.1813-b.

2. Berton G, Cordiano R, Palmeri R, et al. Microalbuminuria during acute myocardial infarction; a strong predictor for 1 year mortality. Eur Heart J. 2001; 22(16):1466-75. doi: http://dx.doi.org/10.18203/2349-3933.ijam20170523.

3. Deveci OS, Kabakci G, Tulumen E, et al. The relationship between microalbuminuria and the presence and extent of coronary atherosclerosis. Angiology 2010;61(2):184-91. doi: $10.14740 /$ jocmr2785w.
4. Schrader J, Luders S, Kulschewski A, et al. Microalbuminuria and tubular proteinuria as risk predictors of cardiovascular morbidity and mortality in essential hypertension: final results of a prospective long-term study (MARPLE Study). J Hypertens. 2006;24(3):541-8. doi: 10.1097/01. hjh.0000209991.48928.c4.

5. P. Karki, K.K. Agrawaal, M. Lamsal, and N.R. Shrestha. Predicting outcomes in acute coronary syndrome using biochemical markers. Indian Heart J. 2015 Nov-Dec; 67(6): 529-537. doi: 10.1016/j.ihj.2015.06.029.

6. Basu A, Jhala JS. Association of microalbuminuria in nondiabetic and non-hypertensive patients with myocardial infarction. Int J Adv Med. 2015;2(3):196-200. doi: http://dx.doi.org/10.18203/2349-3933.ijam20150003.

7. Bhalavi V, Ghanekar G. Correlation of Microalbuminuria and Multiple Risk Factors in Acute Coronary Syndrome. Int J Sci Res. 2016;5(3):187-91. doi: 10.4103/0971-4065.43690.

8. Memon AG, Kolachi M. Relationship of Microalbuminuria in Non-Diabetic and Non-Hypertensive Patients with Acute Myocardial Infarction. J Clin Exp Cardiolog. 2015;6(9):403. doi: $10.4172 / 2155-9880.1000403$.

9. Kumar Jha P, Ete T, Malviya A, et al. Microalbuminuria: Correlation With Prevalence and Severity of Coronary Artery Disease in Non-Diabetics. J Clin Med Res. 2017 Oct;9(10):838-843. doi: $10.14740 /$ jocmr2785w.

10. Patel SR, Acharya H, Saiyad M. A study of predictive value of microalbuminuria in early outcome of non-diabetic patients of acute myocardial infarction. Int J Adv Med. 2017;4(2):3348. doi:

http://dx.doi.org/10.18203/2349-3933.ijam20170523.

11. Srinivasan MP, Kamath PK, Manjrekar PA, et al. Correlation of severity of coronary artery disease with insulin resistance. N Am J Med Sci. 2013;5(10):611-614. doi:10.4103/19472714.120799 .

12. Silva RP, Cisne K, de Oliveria JM, et al. Determination of Microalbuminuria in Hypertensive Patients and in Patients with Coronary Artery Disease. Arq Bras Cardiol. 2008;90(2):99-103. doi: http://dx.doi.org/10.1590/S0066-782X2008000200006.

13. Bhalavi V, Ghanekar G. Correlation of Microalbuminuria and Multiple Risk Factors in Acute Coronary Syndrome. Int J Sci Res. 2016;5(3):187-91. Paper ID: NOV161805.

14. Al-Saffar HB, Nassir H, Mitchell A, et al. Microalbuminuria in non-diabetic patients with unstable angina/non ST-segment elevation myocardial infarction. BMC Res Notes. 8:371 (2015). doi: 10.1186/s13104-015-1347-x.

15. Zeehan A, Ahmad Z, Tahir GA, Yaqoob Y. Acute coronary syndrome; microalbuminuria as atherosclerotic risk factor and its association. Professional Med J. 2017;24(1):26-30. doi: 10.1186/s13104-0 15-1347-x 
16. Kim YS, Kim HS, Oh HY, et al. Prevalence of microalbuminuria and associated risk factors among adult Korean hypertensive patients in a primary care setting. Hypertens Res. 2013;36(9):807-23. doi: 10.1038/hr.2013.44.

17. Liu X, Liu Y, Chen Y, et al. Body mass index (BMI) is associated with microalbuminuria in Chinese hypertensive patients. Int J Environ Res Public Health. 2015;12(2):19982008. doi: 10.3390/ijerph120201998.
18. Aziz KMA. Association of Microalbuminuria with Ischemic Heart Disease, Dyslipidemia and Obesity among Diabetic Patients: Experience from 5 Year Follow up Study of 1415 Patients. Biogenetics. 2014;3(2):118. doi:10.4172/21677662.1000118 .

19. Cirillo M, Senigalliesi L, Laurenzi M, et al. Microalbuminuria in nondiabetic adults: relation of blood pressure, body mass index, plasma cholesterol levels, and smoking: The Gubbio Population Study. Arch Intern Med. 1998;158(17):1933-9. doi: 10.1001/archinte.158.17.1933. 